\title{
The Role of Marketing in Understanding and Controlling Cost of Quality
}

\author{
Sergey Komissarov ${ }^{1}$, Andreas Eklund ${ }^{2} \&$ Mehmet Kocakulah $^{1}$ \\ ${ }^{1}$ University of Wisconsin - La Crosse, United States \\ ${ }^{2}$ Linnaeus University, Sweden \\ Correspondence: Sergey Komissarov, University of Wisconsin - La Crosse, United States
}

Received: December 28, 2020; Accepted: January 12, 2021; Published: January 13, 2021

\begin{abstract}
In the accounting realm, quality is an increasingly important element in planning, production, distribution and branding of goods and services because of global competition and other external factors in many industries. However, the cost of quality must also be considered as not to add unwanted or unwarranted costs to pass along to the end-customer. Marketing professionals are trained to strategically build and protect their own brand, which may consist of products or services. To achieve high-quality, it is imperative that the accounting and marketing departments work together. The four categories of Quality Costs (Prevention, Appraisal, Internal Failure and External Failure) encompass many different quality activities at different stages in producing goods or services. The research and experiences in the marketing industry based on branding will help to show that most quality initiatives are in fact preventative when the end goal is maintaining a solid consumer base and satisfied consumers. As this study shows, treating the brand as an experiential entity serves as a quality facet. This alludes that quality is a facet linking accounting and branding.
\end{abstract}

Keywords: accounting, branding, consumer satisfaction, cost, experiential entity, marketing, quality, and quality costs principles

\section{Introduction}

In today's very competitive marketplace, companies are no longer bound by geographic boundaries. With markets increasingly reliant on global suppliers, the importance of quality has increased. Quality is a critical element for manufacturing, construction and service industries. However, it is easy to spend too much on quality as many companies found following the initial infatuation with the quality revolution of the 1980s and 1990s (Rust et al., 1995). In some cases, winners of prestigious quality awards have gone bankrupt due to unsustainable levels of spending on quality (Hill, 1993). In another example, a company, which was previously spending millions on quality improvements in order to be able to compete for the Deming Prize, ended up dismantling its quality program in order to rein the costs in (Wiesendanger, 1993). These lessons and others have made it very clear that products and services must be developed with a careful eye on the end result, and many companies are paying close attention to the costs associated with quality. For just as the development of a quality product is important, so are the total costs passed on to the customer. While adding costs to ensure quality is a noble cause, it can add price increases to the end product, perhaps causing the customer to choose lower-priced option products. Thus, quality, defined as "a degree of excellence" (Webster, 2013), is an important trade-off and should be pursued with efficiency and purpose.

Understandably, the balance of cost and quality has caused companies to track the costs of quality more explicitly. "The objective is to minimize the total quality cost, which consists of prevention cost and failure cost, in order to search for optimal quality and avoid considerable trade-offs between project costs and project quality" (Fu and Zhang, 2016). Costs of quality are most often discussed with relation to production and distribution of physical goods, but the same rules apply to service industries. In both cases, the marketing function needs to be playing a major role in the quality promise of a company. As Philip Kotler noted, the main purpose of marketing is attracting and retaining profitable customers (Caruso, 1992). Quality plays a very important role in fulfilling this purpose. Being able to advertise and deliver high-quality offering helps attract and retain customers. For this to succeed in the contemporary society, marketing research points out the necessity of consumer experience via the human senses (Achrol and Kotler, 2012). Thus, to ensure satisfying the customers calls for accounting to consider the quality facet of brands, where consumer experience plays an imperative role. 
In this paper, we argue that marketing, specifically branding, needs to be heavily involved in managing not only the quality of the goods or services but also the cost of quality for the company. It is easy to see that positioning the brand with quality-related activities generates costs. On the other hand, research capabilities and expertise of marketing departments (or consultants) can be utilized to help management understand the optimal level of qualityrelated expenditures. It is not a widespread practice as of yet. Even systematic tracking of the quality costs is not something a majority of companies are capable of doing yet. One of the studies has found that only a third of organizations systematically track costs of quality due to challenges involved in measuring such a cost (Sower and Quarles, 2003). It is possible, that a closer involvement of the branding activities could help companies manage the cost of quality more effectively.

Traditionally the perception of the quality has been studied in regard to manufacturing costs, to ensure superior products. However, brands are intangible assets and quality facets for both companies and customers. Thus, quality is a facet both for accountants and marketers. Accounting may help calculate profitability of customer-segments, components to manufacture a high-quality product, and branding costs (Kotler and Keller, 2016). Although marketing research points out the importance for branding in regard to quality (Kirmani and Zeithaml, 1993), little is known when it comes to the cost of quality regarding the on-going communication between customer and corporation. Thus, this paper sets to bridge accounting and marketing by viewing the brand as a quality facet.

\section{Costs of Quality Categories and Marketing Support}

Quality costs are most simply defined as costs in excess of those that would have been incurred if a good were manufactured or service provided exactly right the first time (Crosby, 1979). While there are obvious applications when considering replacement costs or repair issues, there are actually four categories of quality costs for which firms and organizations should account. The four categories include preventative costs, appraisal costs, internal failure and external failure (Defeo and Juran, 1998).

Marketing departments have long been the responsible party for maintaining a company's quality perception, in which the brand is part of that oversight. Before addressing specifically how a marketing team may help with quality, it is important first to understand the role of strategic communications. Marketing departments may differ in their roles at different organizations. At large manufacturing firms, such as automobile companies, the marketing professionals must oversee advertising, web communications and employee communications to name a few responsibilities. At a small company, they may not be able to afford and maintain a full-service internal marketing department, but they may hire an outside agency to perform the same services. Whether internal or external, brand integrity is critical to building long-term customers and keeping a competitive edge. Customers want to rely on a quality product with predictable performance and consistent results.

The marketing department handles branding a product or service in a strategic and thoughtful way. They are also responsible for public relations. Public relations are the communications done with current, potential and all other customers that focus the message through external channels like social media, news media and objective analysis. Such communications are especially important if a company's image is tarnished through a scandal, product recall or another public failure. For example, despite the Volkswagen scandal may be a reputation-damaging event (Gatzert, 2015), strong brands strongly increase the likelihood for customer forgiveness (Fetscherin and Sampedro, 2019). The promise of quality during a public relations crisis is critical to recovering from the event, and branding plays an imperative part as such things unfold. While this type of "external failure" warrants obvious help from the marketing department, the other areas of quality costs can also benefit from communications support. Preventative assessments, appraisal checks, internal failures and external failures should justify the help of communications specialists. These specifics will be covered in the following section.

\section{Quality Cost Categories and Branding}

Preventative costs are the first opportunity to maintain and ensure quality and are especially relatable to the marketing department. The development stage is the best opportunity to both ensure the quality of the product and control costs (Anderson and Sedatole, 1999). Preventive costs are the costs associated with preventing defects and other quality problems. They can include education of suppliers, certification of employees, team training, product redesign and service improvements.

Brand managers can be an excellent ally with production managers. An illustrative example is Starbucks. Employees such as baristas are educated in expresso excellence training to ensure a substantial understanding of the innovative product range and more efficiently use the machines to deliver a quality product to the customers. In addition, all employees are educated in Starbucks core values so the company can have two-way communication with the customers in the stores (Kohnen, 2012). Thus, the company can efficiently oversee the cost per unit and simultaneously ensure quality to the customers. In addition, supplier education, which is by definition 
preventative, can be achieved via a training video. Consider a forklift manufacturer who sells their machinery to equipment distributors. Improper transport or storage may seriously damage the equipment, compromising the integrity of the machine and the eventual use to the end customer. A training video, scripted and produced in conjunction with the marketing department can help avoid those very costly misuses. This is just one example of an up-front cost dedicated to preventing mistakes, which could save important resources in the long run.

Another type of preventative cost is product redesign or product improvements. Brand managers or marketing agencies often work hand-in-hand with research and development teams. Research is a very important element of the marketing process, and professionals are trained to interview and poll customers to find the product features and types that best serve their needs. Focus groups, phone surveys and even shopping mall polling are common types of research, which can generate important qualitative and quantitative data for design and improvements. Such costs are incurred before production starts but are necessary to make sure companies bring the right product to market and do not waste corporate time and materials on a poorly researched proposition. Research can help prevent the production of a lackluster product that will not have marketplace support.

A similar process can be followed for a service redesign or improvement. Branding researchers can identify aspects of a service where customers may desire improvement. After that, branding researches can help management decide which of the potential improvements are likely to be most profitable. For large companies, pilot testing of improvements in limited markets can be performed in order to determine effectiveness and profitability. Based on such testing, financial projections can be developed to better understand the implications of full-scale implementation of the quality improvements before committing resources to a quality improvement program. By working closely with brand managers or consultants, management can maximize the likelihood of realizing profitability increases from their quality initiatives.

Quality costs can also include those devoted to inspections, testing and other activities designed to determine if a problem exists before a product is delivered. Unlike preventative costs, which are aimed at finding problems before production, these costs, called appraisal costs, are the next lines of defense in a total quality promise. Brand managers would likely not be involved directly in the inspections and testing, but they can certainly assist those departments in their activities. For instance, the inspection team must know the criteria by which they are judging the materials. Brand managers might be involved in creating checklists to use during the inspection. It might also include training pieces to help inspectors identify common areas of weakness or trouble spots in the process. As another example, consider a magazine publisher. While not a traditional manufacturer of goods, they certainly provide a product consumed by millions of readers and information seekers. Brand managers can provide editing services to catch typographical errors or print production issues before the magazines hit newsstands. A marketing firm or internal department is the manager of the company's brand, and such inspections and quality tests are critical to delivering on the brand promise. In this case, where the product itself is a communication piece, the marketing department's role is obvious and important.

The next opportunity for quality costs to accumulate also occurs after production. Internal failure costs include all activities to correct a problem before a good or service is delivered. This might include costs associated with scraping a product or reworking an error after such a problem was discovered in the appraisal stage. Using the previous example of the magazine publishing house and the marketing department as the editors, if errors are found in a magazine prior to mailing, the costs and extra time needed to make corrections or swap out photos can be considered an internal failure cost. Internal cost is a large area of opportunity for marketing to focus on. For example, one study reported the internal failure costs of $7.147 \%$ of sales during the period, on average (Cermakova and Bris, 2017). As such, internal failure has a significant effect on the cost of quality.

The area that stands to gain or lose the most from customer interaction is that of external failure. If a product or service is found to be defective or malfunctioning before it is delivered, the fix is an internal cost. However, if the faulty product has been delivered or the service poorly performed, then the cost is external. This can include costs associated with refunds, warranty issues, repairs, replacements, liability costs, and repeat service deliveries. There are certainly physical and measurable costs to be accounted for if a good has been repaired or replaced, but arguably the most damage stands to occur with the loss of future business from that dissatisfied customer.

\section{Brand as a Quality Facet}

Building a strong brand provides advantages in the market (Aaker, 2002; Mizik, 2014). Since the brand is an intangible asset and the quality perception resides in the customer's mind, it must be strategically maintained and communicated. Understanding quality perception involves identifying strong and unique associations held in customer memory (Keller, 1993). Consider a customer who is hungry at a food court. The customer will (sub) consciously evaluate the various restaurant brands based on previous encounters accessed in the memory. The 
associations will influence which restaurant to eat at. For example, let's say the customer decides on a McDonald's meal. The selection can be explained from held brand associations. In regard to quality brand, the customer will associate McDonald's with consistent, fresh, hot, and good tasting. Other associations related to the McDonald's meal are service - clean, consistent, convenient, fast, hassle-free, value - pricing, portion size, and promotion. Also, a known product at McDonald's, for example, BigMac plays an important role in their choice (John et al., 2006). Thus, familiar menus, tested recipes, and consistent experience regardless of the location or franchise is a part of is the quality facet conveyed by the brand.

Aside from the fast-food counter, the brand serves as a quality facet for everything from automobile (Wiedmann et al., 2011) to tourism destinations (Moon and Han, 2019). In regard to this, it can be seen that the brand is a quality initiative that helps deliver the experience. This reasoning follows the logic of Pine and Gilmore (1998) who emphasize the necessity for companies to move beyond the product or service utility by focusing on experiences. Moreover, Schmitt (1999) states that consumers take quality for granted, whereof, companies need to deliver a memorable experience. However, due to the outcome of an experience being determined by the consumer, companies can only provide various cues to be seen, heard, tasted, smelled, and touched (Pine and Gilmour, 1998). Thus, delivering an experience can encompass preventative activities in test market research, or using the example of a fast-food restaurant, also include training cooks and order takers to deliver the brand experience. Initiatives can also include activities after the fact, too. In the result of a problematic visit to a fastfood restaurant, a uniform and brand-conscious response to a customer complaint is certainly an external failure situation that will benefit from a solid brand and good quality programs. Specifics relating to external failure will be discussed in the following sections.

\section{Social Media and One-on-One External Failures}

Damage to a brand can occur on a large or small scale. If the external failure occurs as part of one-on-one customer interaction, unfortunately, one unhappy customer can damage the company reputation with "word-of-mouth" messaging. Thus, "external failure costs are very dangerous for the company because the high costs in this category can lead to loss of customers to the worsening corporation reputation" (Cermakova and Bris 2017). Social media has afforded new power to bad public relations via word-of-mouth because the platform is much larger due to the increasing popularity of social media like Twitter, Facebook, Snapchat, WhatsApp and Instagram. Research illuminates that customers tend to rely more on other customers than on information from the brand. Although social media is a tool for two-way communication between the brand and customers, negative information tends to spread rapidly. Although negative comments are not necessarily bad, companies need to carefully manage social media by being up to date and interacting with customers (de Vries et al., 2012). Euan Semple brings social media to the forefront, as he advises corporations on how to integrate this viral communication device into their messaging (Semple, 2009) In other words, the same oversight that a brand manager might give to printed advertising or official announcements, should also be given to a company's social media platforms. Likewise, careful monitoring mechanisms should be in place to gauge customer attitudes in the social media realm, beyond the corporation's page and on the individual customers' blogs, pages and posts. Although this medium is less controllable by its very nature, ignoring it can have drastically negative results. Semple's urging to have officials responsible will help maintain connections and customer loyalty by showing emphasis on quality communication and devotion to feedback, allowing potential failures to be identified more quickly and then handled efficiently. It will also show the company's awareness of new technology and its ability to adapt to modern communication trends. Social media, therefore, can be an asset in the case of external failure, but it can also be part of the company's overall quality program simply by pre-emptively showing another communication vehicle ready to relay messaging to customers.

\section{Public Relations in Crises Management}

Businesses incur external failure costs, as earlier stated, when a problem occurs after the product has been delivered to a customer. This might include warranty costs, liability costs, replacement costs or most importantly the cost of lost business. However, when the failure is large and made public, the damages can go beyond the immediately affected customers and cause a long-term impact on the brand. The resulting brand repair and failure management is a classic use of public relations and is critical to preventing the loss of future business. Such communication (news conferences, press releases, photoshoots, events, etc.) with the marketplace is extremely important. Some insurance groups are now offering a new type of coverage to help companies offset the cost of expert public relations management (Holm, 2011). The cost of such a policy depends on the size of the company, the complexity of their response plan, and the risk for crisis management services, but a small company might expect a preparedness plan to start at $\$ 10,000$ for their annual premium. 
An illustrative example of a very real public relations crisis was cruise line debacle aboard the Carnival Triumph. What started, as an engine fire quickly became an eight-day ordeal with scarce food, unusable facilities and sweltering heat. Tom Donahue, an expert in crisis communications said that although Carnival might have made the right operational decisions, their communication was lacking (Mungin and Morgenstein, 2013). Another example happened in the fall of 2016 when Wells Fargo made headlines for opening a couple of million fake accounts. They have been marketing to regain customers trust since (Pasquarelli, 2016). The bank continues its marketing through social media, radio, and more to re-establish their brand by marketing to gain customer trust.

Some argue that any publicity is good publicity, but there must be a balance between costs and how much external failure to accept (Farther and Morse, 1998). Customer confidence can weaken following any external failure. Some are massive public relations events, like Carnival, but even one-on-one service or product failures will require corrective brand management. Many companies now follow up on external failures, such as a replacement product, with an email or phone survey to gauge satisfaction. Follow-up communications can be helpful in large-scale crises management, social media brand control and one-on-one relationship repair.

\section{Value of Quality Programs}

In 1989, Xerox introduced a cost of quality program to their U.S. Sales and Marketing Group, a service business charged with purchasing supplies and equipment and selling them throughout the United States (Carr, 1992). The company's experience with the new cost of the quality program has saved them more than $\$ 200$ million in just four years. Perhaps even more impressive was the fact that this program did not include layoffs or painful costcutting and most of the managers, although skeptical at first, began to see the value in this quality program. Through identifying and addressing inefficiencies in their processes, they sought to deliver $100 \%$ customer satisfaction. After studying Xerox's experience, it was concluded that the most important element to a strong quality program is the culture. "Managers need to be comfortable with the use of estimates and trust the judgment of financial managers. Most importantly, a sustained program must avoid the temptation of using COQ as an individual or department performance measure (Carr, 1995).

Communications are pivotal to the successful implementation of a culture of quality. Just as the brand managers or agency is responsible for external communications, they are also very helpful in maximizing internal communications. Marketing professionals, for example, often handle employee newsletters. Such newsletters can include testimonials, success stories, events and featured team-members, and when done well can be a major influence on the culture of a business.

Building on Carr's (1995) notion that the culture of a business is critical to a successful cost of the quality program, Durmaz and Sevil (2012), argue that the basic elements of management philosophies must begin with a change in marketing philosophies or a change in culture. There must be a shift to focus all efforts on customer satisfaction and thus to adhere to quality-based production best practices. Moreover, quality planning must be a part of the company's annual forecast. Marketing departments and firms are often charged with the task of developing a strategic plan for company communications and branding efforts. Aligning the quality plan and the strategic communications plan, will allow the company to set their sights on a common goal and to emphasize that the quality of their business relies on the quality of their output. Their output is just as reliant on their product manufacturing or service development as it is on their internal and external communications.

Recognizing that a quality program should focus on more than just "accounting", data was another finding by Carr (1992) in Xerox's culture. Specifically, "management accounting should focus on a network of studies rather than a single massive system". The same applies to the cost of quality analysis and oversight. Marketing cannot align with every cost of quality category as a perfect fit; however, it can support all aspects of the quality program, corporate planning and company brand.

\section{Conclusion}

The aim of this paper was to bridge the quality cost principles in accounting with marketing literature. The quality costs principles are important not just for identifying product defects, but also in avoiding customer dissatisfaction. Thus, from an accounting perspective, the quality cost principles are all related to preventing customer complaints and dissatisfaction in the manufacturing process. However, this does not per se lead to quality for the consumers. As Moorman and Rust (1999) concluded, "marketing is best viewed as the function that manages connections between the organization and the customer". With this in mind, the current paper points out the necessity to move beyond the quality cost principles and consider the brand as a quality facet. In the experience economy, an offered quality product is not enough for consumers. Rather, the focus is on treating the brand as an experiential entity, which can be seen, heard, smelled, touched, and/or tasted leading to quality for the consumers. This bridging moves beyond the traditional aspect of quality in the production by illuminating that the brand serves as a quality 
facet in the consumer's mind. Even so, firms may not need to consider all quality cost principles since it does not necessarily result in sales and profit. Therefore, firms are advised to consider the brands as a quality facet in a crowded marketplace. Since the brand is an intangible asset that situates quality in the consumer's mind, it may not be recognized as belonging with the quality cost principles. Thus, the novelty of the paper lies in bridging accounting and marketing literature, where the brand is an experiential entity that must be strategically maintained and communicated from an accounting point of view.

\section{References}

Achrol, R. S., \& Kotler, P. (2012). Frontiers of the marketing paradigm in the third millennium. Journal of the Academy of Marketing Science, 40, 35-52. https://doi.org/10.1007/s11747-011-0255-4

Anderson, S. W., \& Sedatole, K. (1998). Designing quality into products: The use of accounting data in new product development. Accounting Horizons, 12, 213-233.

Carr, L. P. (1992). Applying cost of quality to a service business. Sloan Management Review, 33, $72-77$.

Carr, L. P. (1995). How Xerox sustains the cost of quality. Management Accounting [USA], 77, 26-32.

Caruso, T. E. (1992). Kotler: Future Marketers will Focus on Customer Data Base to Compete Globally. Marketing News, 26, 21-22.

Cermakova, M., \& Bris, P. (2017). Managing the costs of quality in a czech manufacturing company. Scientific Papers of the University of Pardubice. Series D. Faculty of Economics and Administration; Pardibuce, 41, $1-17$.

Crosby, P. (1979). Quality is Free. New York: McGraw-Hill.

de Vries, L., Gensler, S., \& Leeflang, P. S. H. (2012). Popularity of Brand Posts on Brand Fan Pages: An Investigation of the Effects of Social Media Marketing. Journal of Interactive Marketing, 26, 83-91. https://doi.org/10.1016/j.intmar.2012.01.003

Defeo, J. A., \& Juran, J. M. (1998). Juran's quality handbook: the complete guide to performance excellence. $5^{\text {th }}$ edition. New York: McGraw Hill.

Durmaz, Y., \& Sevil, Z. (2012). A Theoretical Approach to the Concept of the Costs of Quality. International Journal of Business and Social Science, 3, 83-86. https://doi.org/10.24297/ijct.v14i11.1810

Fetscherin, M., \& Sampedro, A. (2019). Brand forgiveness. Journal of Product \& Brand Management, 28, 633652. https://doi.org/10.1108/jpbm-04-2018-1845

Fu, F., \& Zhang, T. (2016). A New Model for Solving Time-Cost-Quality Trade- Off Problems in Construction. PLoS One, December, 1-15. https://doi.org/10.1371/journal.pone.0167142

Gatzert, N. (2015). The impact of corporate reputation and reputation damaging events on financial performance: Empirical evidence from the literature. European Management Journal, 33, 485-499. https://doi.org/10.2139/ssrn.2576627

Hill, R. C. (1993). When the Going Gets Rough: A Baldrige Award Winner On the Line. Academy of Management Executive, 7, 75-79. https://doi.org/10.5465/ame.1993.9411302351

Holm, E. (2011). Got a Crisis? Tap AIG (Really). The Wall Street Journal.

John, D. R., Loken, B., Kim, K., \& Monga, A. B. (2006). Brand Concept Maps: A Methodology for Identifying Brand Association Networks. Journal of Marketing Research, 43, 549-563. https://doi.org/10.1509/jmkr.43.4.549

Keller, K. L. (1993). Conceptualizing, Measuring, and Managing Customer-Based Brand Equity. Journal of Marketing, 57, 1-22. https://doi.org/10.2307/1252054

Kirmani, A., \& Zeithaml, V. (1993). Advertising, Perceived Quality, and Brand Image. In: AAKER, D. A. \& BIEL, A. L. (eds.) Brand equity \& advertising: Advertising's role in building strong brands. Hillsdale, NJ: Lawrence Erlbaum Associates Inc.

Kohnen, J. (2012). Onward: How Starbucks Fought for Its Life Without Losing Its Soul. Quality Management Journal, 19(2), 64-64. https://doi.org/10.1080/10686967.2012.11918349

Kotler, P., \& Keller, K. L. (2016). Marketing Management, New Jersey, Pearson

Mizik, N. (2014). Assessing the Total Financial Performance Impact of Brand Equity with Limited Time-Series Data. Journal of Marketing Research, 51, 691-706. https://doi.org/10.1509/jmr.13.0431 
Moon, H., \& Han H. (2019). Tourist experience quality and loyalty to an island destination: The moderating impact of destination image, Journal of Travel \& Tourism Marketing, 36, 43-59. https://doi.org/10.1080/10548408.2018.1494083

Moorman, C., \& Rust, R. T. (1999). The role of marketing, Journal of Marketing, 63, 180-197. https://doi.org/10.2307/1252111

Mungin, Lateef \& Morgenstein, Mark. (2013). "Carnival cruise line in more troubled waters." CNN.com. Cable News Network. Retrieved from http://www.cnn.com/2013/03/15/travel/carnival-problems/index.html

Pasquarelli., A. (2018). "WELLS FARGO RAMPS UP MARKETING IN PUSH TO REGAIN TRUST.” 13 October 2016. Retrieved May 27, 2018, from http://adage.com/article/cmo-strategy/wells- fargo-rampmarketing/306303/

Pine, B. J. I., \& Gilmore, J. H. (1998). Welcome to the experience economy. Harvard Business Review, 76, 97105.

Quality. (2013). Merriam-Webster.com. Merriam-Webster, 2013. Web. 16 April 2013.

Rust, R., Zahorik, A. J., \& Keiningham, T. J. (1995). Return on quality (ROQ): Making service quality financially accountable. Journal of Marketing, 59, 58-70. https://doi.org/10.2307/1252073

Schmitt, B. (1999). Experiential marketing. Journal of Marketing Management, 15, 53-67. https://doi.org/10.1362/026725799784870496

Semple, E. (2009). Update Your Crisis Comms Plan with Social Media. Strategic Communication Management, 13, 7-7. https://doi.org/10.26226/morressier.5b0445aaa874c6001b34eba3

Sower, V. E., \& Quarles, R. (2003). Cost of quality: why more organizations do not use it effectively. In: ANON, eds. Proceedings of Annual Quality Congress, 2003 Milwaukee, WI. American Society for Quality, 57, 625, 637.

Wells Fargo settles shareholder lawsuits for $\$ 480$ million. (2018, May 4). Retrieved May 27, 2018, from CBS News https://www.cbsnews.com/news/wells-fargo-settles-shareholder- lawsuits-for-480-million/

Wiedmann, K. P., Hennigs, N., Schmidt, S., \& Wuestefeld, T. (2011). Drivers and Outcomes of Brand Heritage: Consumers' Perception of Heritage Brands in the Automotive Industry. Journal of Marketing Theory and Practice, 19, 205-220. https://doi.org/10.2753/mtp1069-6679190206

Wiesendanger, B. (1993). Deming's Luster Dims at Florida Power \& Light. Journal of Business Strategy, 14, 60 61. https://doi.org/10.1108/eb039590

\section{Copyrights}

Copyright for this article is retained by the author(s), with first publication rights granted to the journal.

This is an open-access article distributed under the terms and conditions of the Creative Commons Attribution license (http://creativecommons.org/licenses/by/4.0/). 